Portland State University

PDXScholar

Summer 9-23-2014

\title{
Sleep Quality and Quantity of Portland State University Intercollegiate Student-Athletes: A Case Study
}

Mara Elizabeth Birge

Portland State University

Follow this and additional works at: https://pdxscholar.library.pdx.edu/open_access_etds

Part of the Mental and Social Health Commons

Let us know how access to this document benefits you.

\section{Recommended Citation}

Birge, Mara Elizabeth, "Sleep Quality and Quantity of Portland State University Intercollegiate StudentAthletes: A Case Study" (2014). Dissertations and Theses. Paper 1984.

10.15760/etd. 1983

This Thesis is brought to you for free and open access. It has been accepted for inclusion in Dissertations and Theses by an authorized administrator of PDXScholar. For more information, please contact pdxscholar@pdx.edu. 
Sleep Quality and Quantity of Portland State University Intercollegiate Student-Athletes:

A Case Study

by

Mara Elizabeth Birge

A thesis submitted in partial fulfillment of the requirements for the degree of

\author{
Master of Science \\ in \\ Health Studies
}

Thesis Committee:

Gary Brodowicz, Chair

Jim Wallis

Jonathan Huwe

Portland State University

2014 
(C) 2014 Mara Elizabeth Birge 


\begin{abstract}
According to the National Collegiate Athletic Association (NCAA) rulebook, student-athletes are limited to 20 hours/week of official athletic activity. While this in and of itself is not a huge time commitment, when it is combined with the academic expectations that come with being a college student and athletic activities that are not included in the 20 hours/week, there isn't much time left in the week for student-athletes to get everything done. In addition to imposing daily stress, such time demands may negatively affect sleep. This study examined the sleep quality and quantity of studentathletes, as well as how much time they spend on athletic and academic activities. It was predicted that the student-athletes overall would not have a "good" sleep rating, and that they would not be getting the recommended 10 hours of sleep per night. It was also predicted that in-season student-athletes would be spending more than the allotted 20 hours per week on their athletic activities.

All data for this study were collected through online surveys, which included several demographic and background questions, and the Pittsburgh Sleep Quality Index (PSQI), an instrument that provides a measurement of an individual's sleep quality. A score $\leq 5$ is considered "good" sleep quality, while a score $>5$ is considered "bad" sleep quality. The 42 participants in this study (29 female; 13 male) were student-athletes at Portland State University (PSU) and represented all but one of the sports offered at PSU. All student-athletes listed on the official team roster received two e-mails requesting their participation in the study. There was at least one respondent in each class level, with 13 reporting as in-season student-athletes and 29 reporting as out-of-season student-athletes.
\end{abstract}


Of the 42 respondents, only 3 received a "good" sleep quality rating. The median sleep quality rating for the entire sample was 9, and the median amount of sleep obtained was 7 hours/night, with a median bedtime of 2330. The median amount of self-reported time spent on athletics was 15.5 hours/week and the median time spent on academics was 15 hours/week.

It was concluded that PSU student-athletes do not get enough sleep, and their sleep quality is very low. In-season student-athletes also self-reported spending more time in their athletic activities than the maximum NCAA limit. Although the sample size was small, these data support the need for increased education about the benefits of sleep. Also, an examination of the policies regarding what qualifies as an athletic activity, and how much time athletes should spend on such activities is recommended. 
Table of Contents

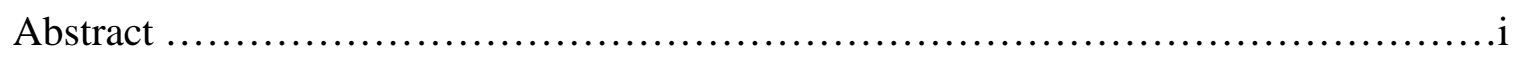

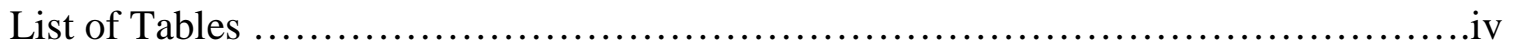

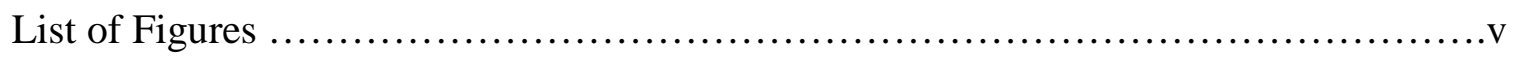

Chapter 1

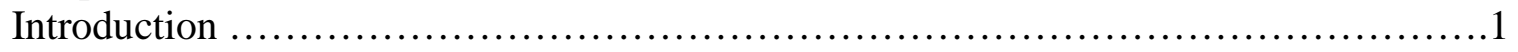

Chapter 2

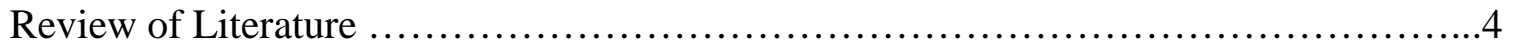

Chapter 3

Methods .....................................................................11

Chapter 4

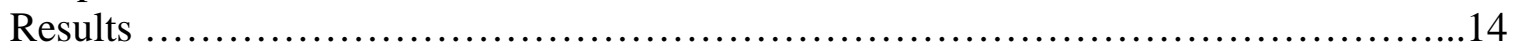

Chapter 5

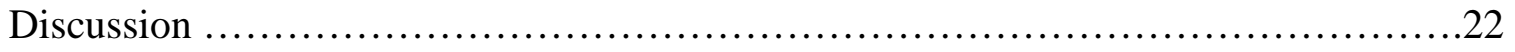

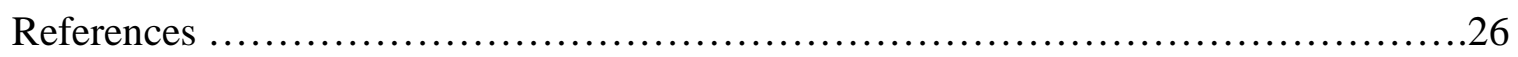

Appendices

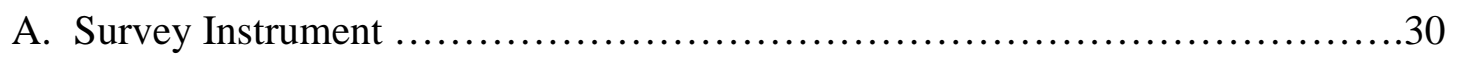

B. Permission to Use Pittsburgh Sleep Quality Instrument .......................35

C. Human Subjects Approval .............................................. 36

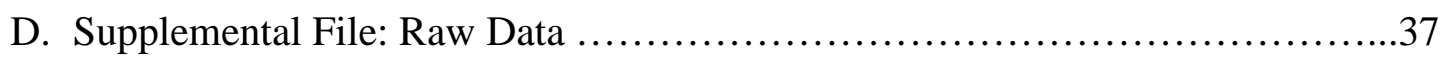


List of Tables

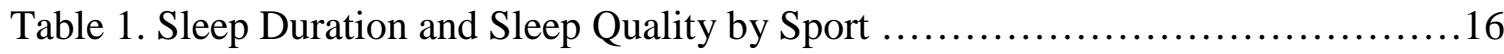

Table 2. Time Spent on Athletics vs. Academics by Sport .........................20

Table 3. Sleep Duration and Sleep Quality by Season Classification ..................21

Table 4. Time Spent on Athletics vs. Academics by Season Classification ..............21 
List of Figures

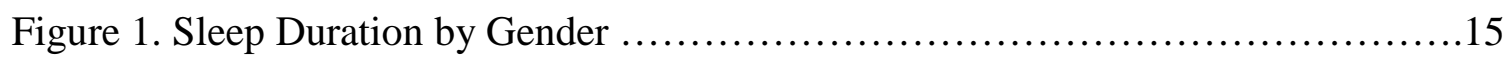

Figure 2. Sleep Duration by Class Standing ......................................15

Figure 3. Sleep Duration by Season Classification …................................15

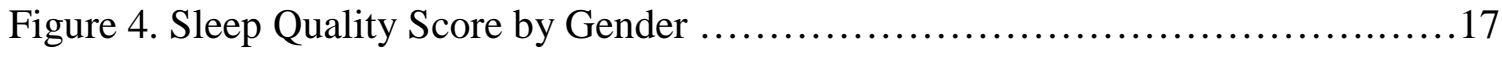

Figure 5. Sleep Quality Score by Class Standing ..................................17

Figure 6. Sleep Quality Score by Season Classification ................................17

Figure 7. Time Spent on Athletics vs. Academics by Gender ..........................19

Figure 8. Time Spent on Athletics vs. Academics by Class Standing ....................19

Figure 9. Time Spent on Athletics vs. Academics by Season Classification ..............19 
Chapter 1: Introduction

In Division I college athletics, coaches continually strive to get the most out of their student-athletes as they can. This means having them spend as much time as possible at practice, studying film, and in the weight room. The National Collegiate Athletic Association (NCAA) limits the amount of time student-athletes can spend in sport-related activities to 4 hours/day, with a maximum of 20 hours/week (NCAA, 2013). These activities include practices, mandatory weight training, supervised individual workouts, games, meetings with coaches, and film sessions. However, the time limit does not include study hall, injury rehabilitation and treatments, travel, recruiting activities, compliance and academic meetings, and voluntary workouts and meetings. Although sport-related activities are technically limited to those 4-hours a day, some coaches disregard the regulation. Practices rarely end at their scheduled times, and many extra workout or film review sessions are considered "optional," but pressures for athletes to attend are considerable. Unless a complaint is filed, there is very little oversight to determine whether or not these violations occur on a regular basis. Also, if the offense is not egregious, violating the 20 hour/week limitation often has no serious repercussions.

In addition to all of their sport-related activities, athletes must attend classes and complete assignments for a full-time credit load at their institution. A full-time credit load is usually considered 12 credit hours per semester/quarter. That is equivalent to approximately 32 hours of mandatory activities every week, not including homework assignments and other excluded athletic activities. Hypothetically, a student-athlete could easily spend at least 5 hours per week on homework and other academic activities, and 3 
hours in medical treatment and pre-practice preparation. The total adds up to at least 40 hours a week without even accounting for travel time or any social activities. It is easy to see that the hours add up quickly for student-athletes, and the amount of time for sleep is often compromised. It has been recommended that the average college student get 8-9 hours of sleep per night, while a physically active student should attempt to accumulate 10 hours (Gillen-O’Neel, Huynh, \& Fuligni, 2013). In spite of this recommendation, most college students average less than 7 hours of sleep a night (Orzech, Salafsky, \& Hamilton, 2011).

The potential physical effects of chronic sleep deprivation on athletic and academic performance have been well documented. What is not as well established is whether participation in collegiate athletics systematically forces student-athletes to sacrifice sleep to make time for the other demands in their lives. This is important because the stated goal of intercollegiate athletics is to provide student-athletes an opportunity to participate in athletics while working to earn a degree (NCAA, 2013). Each student-athlete must find a way to balance the demands of maintaining their grades while putting in the necessary time to be successful in their sport. In the competition for an athlete's time, the unfortunate reality is that sports-related commitments almost always become the priority. This is not always the choice of the student-athlete, as they are not usually in a situation where they can make changes that might impact their responsibilities to athletics. As the time demands for athletics increases, so does the pressure to be successful in the classroom. It is difficult for a university to have a successful athletics program if athletes cannot remain academically eligible, which means that athletes have added pressure to 
successfully complete their academic assignments. This is often the root of sleep deficits seen in college athletics; athletics and academics take priority over personal health.

This study examined whether student-athletes meet the recommended levels of sleep quality and quantity, as well as how much of their time is spent on academic and athletic activities. This investigation follows on a study by Dettl (2013), which examined how sleep quality differed between student-athletes and non-athletes. Numerous subjective measures were used to create a sleep profile for collegiate student-athletes that could be compared to non-athletes. Dettl (2013) used surveys to assess sleep quality, daytime sleepiness, and daytime functioning and found that student-athletes had a better sleep profile than non-athlete students. Significant differences were found between the athlete and non-athlete populations in measurements of sleep quality, perceived stress, and overall health. The current study investigated whether student-athletes meet the recommended guidelines for sleep quantity and quality, and also examined how much time is spent on athletic and academic activities.

It was predicted that student-athletes would not meet the recommended standard of 10 hours/night of sleep and that their sleep quality would not be classified as "good." It was also hypothesized that in-season athletes would report spending more than 20 hours/week on their athletic commitments. 
Chapter 2: Review of Literature

\section{Definition of Sleep}

Sleep is a complicated process that has been defined in many different ways. Hobson (1995) defines sleep as a dynamic behavior that is more than "...the absence of waking, sleep is a special activity of the brain, controlled by elaborate and precise mechanisms. Not simply a state of rest, sleep has its own specific, positive functions." This definition highlights the importance of sleep's restorative potential, which is oftentimes forgotten by those that need it most. Sleep can be separated into 2 stages: 1) non rapid eye movement (NREM) sleep, and 2) rapid eye movement (REM) sleep. Sleep normally begins in NREM. NREM has 4 stages of progressively deeper sleep (Venter, 2012). The last 2 stages of NREM sleep are referred to by researchers as slow-wave sleep or deep sleep (Venter, 2012).

Approximately 30 minutes after sleep initiation the individual enters REM sleep. REM sleep is a 20-25 minute period where blood flow, heart rate, respiration, body temperature, and blood pressure all increase (Venter, 2012). During this phase there is a noticeable increase in eye movement and muscle twitching; it is also the phase where dreaming usually occurs.

\section{Circadian Rhythm}

The circadian rhythm is a biological internal clock that regulates sleep/wake cycles and human behavior on an approximately 24-hour schedule (Hayes, Bickerstaff \& Baker, 2010; Venter, 2012). Circadian rhythms are generated through biochemical processes and are not affected by alarm clocks or the environment (Davenne, 2009). 
There is evidence that the circadian rhythm can affect performance, and disturbing the rhythm by limiting sleep may negatively affect performance. Athletic performance tends to peak in the afternoon, between 1200 and 2100 (Hayes, Bickerstaff \& Baker, 2010). There also tends to be a peak in aerobic performance in the evening. Conversely, mental tasks, reaction time, and sustained attention all tend to be reduced in the early morning hours (Davenne, 2009). This is especially important following a period of increased energy expenditure, where the body usually releases hormones to facilitate recovery at night. If an athlete does not get enough slow-wave sleep, they may experience a deficit in their ability to recover from training sessions and competition.

\section{Importance of Sleep}

Sleep has numerous benefits. For example, sleep provides an opportunity for the body to physically and psychologically recover from the day, as well as for the mind to store memories of tasks that were learned that day (Venter, 2012). Physiological revitalization hits its peak during slow-wave sleep while the body's metabolism is at its lowest. There is also a noticeable peak in the secretion of growth hormone (Davenne, 2009). Ninety percent of the production of these and other hormones occurs during NREM sleep, especially in the first cycle of slow-wave sleep (Venter, 2012). This increase in hormone activity can be disrupted when sleep deprivation occurs due to the disruption of the circadian rhythm.

The brain uses sleep to learn tasks that have been practiced during the day (Venter, 2012). The brain has been shown to facilitate delayed learning of a skill, even without further physical practice (Walker \& Stickgold, 2005). This delayed learning is 
only achieved when a period of good quality sleep is completed within 24-hours of training.

Sleep is also important for organizing and implanting new memories (Gillis, 1996). When the brain is able to organize newly formed memories, it makes recall and accuracy better for the next waking period, as well as improving judgment and problem solving abilities. This ability to process new information allows for academic performance to be increased when sleep quality and quantity are within recommended ranges.

Increasing sleep has also been shown to cause a measureable increase in performance (Mah, Mah, Kezirian, \& Dement, 2011). After basketball players increased their nightly sleep time to 10 hours per night for 5-7 weeks they had faster sprint times, higher free throw percentage, higher 3-point field goal percentage, faster reaction times, and decreased daytime sleepiness ratings. This study shows that achieving the recommended amount of sleep can maximize athletic performance as well as personal well-being.

\section{Causes of Sleep Deprivation}

There are many factors that affect sleep-wake cycles. One of the most influential factors is the sleep environment. This includes any noises or lights that can affect a person's ability to fall or stay asleep. Disturbing noises can be caused by anything from traffic to a noisy neighbor. It has been shown that fluctuating noises, such as traffic or talking, is more disrupting to sleep than consistent or constant noises, such as a fan or white noise machine (Öhström \& Skånberg, 2004). 
One of the causes of sleep deprivation that is the most difficult for studentathletes to control is travel. Travel is a major part of college athletics, and students are often on the road for up to 5 days at a time in any given week during their competitive season. Traveling to a different time zone is especially impactful, and can cause an inability to sleep at the local time, increased irritability, moodiness, and headaches (Brooks, Fahey, \& Baldwin, 2009). This “jet lag” can be combated by increasing hydration before the flight, adapting to the new time zone a few days early, increasing macronutrient consumption, and increasing exposure to natural light (Venter, 2012). There is no proven way to combat all of the effects of jet lag, but using these techniques can decrease the negative effects of air travel.

Collegiate student-athletes have many demands placed upon them. They have to maintain peak physical condition to perform at a high level, all while maintaining a successful GPA and functioning in a variety of social settings. These demands can cause increased stress in the student-athlete's life. When sleep is not consistent in quality and quantity, the effects of the stressors of daily life can be compounded and make dealing with future stressors more difficult (Benham, 2010).

\section{Negative Effects of Sleep Deprivation}

Partial sleep deprivation affects all aspects of neurocognitive performance: cognitive, mood, and motor. Although the effects of sleep deprivation are not equal across the three domains, all performance is decreased when compared to baseline or control levels (Pilcher \& Huffcutt, 1996). These decreases in performance are similar to 
decreases that occur with a blood alcohol level of 0.05\%-0.10\% (Williamson \& Feyer, 2000).

Partial sleep deprivation — a characteristic of student-athlete life—affects mood and cognition greater than total sleep deprivation (Durmer, 2009). It has also been shown that cognitive performance becomes progressively worse as time spent on a task increases. Chronic sleep deprivation has also been shown to increase daytime sleepiness, decrease cognitive accuracy, and increase lapses of attention. All of these side effects would be detrimental in a classroom, or during athletic activity. After 2 weeks of continual sleep restriction, the cognitive defects found were the same as after one night of total sleep deprivation (Van Dongen, Maislin, Mullington, \& Dinges, 2003). During longterm studies, cumulative cognitive deficits were seen with a linear increase after every night of restricted sleep.

Effects of sleep deprivation on motor performance include increased fatigue, decreased reaction time, and decreased maximal oxygen uptake $\left(\mathrm{VO}_{2} \mathrm{max}\right)$ (Durmer, 2009; Reilly \& Edwards, 2007; Neylan et al., 2010). A study conducted on soldiers who performed repeated physical activities over a number of days with only two hours of sleep found the soldiers were completely ineffective after only four days of restricted sleep (Reilly \& Edwards, 2007). This was true even when their diets were supplemented with high-energy foods. Another study found that chronic sleep deprivation-coupled with low energy intake—could lower $\mathrm{VO}_{2} \max$ by $8 \%$ (Guezennec et al., 1994).

Reaction time is an important component of athletic performance. Poor reaction time can not only lead to undesired outcomes, but can also increase the risk of injury 
caused by an athlete's inability to react to changing surroundings during athletic participation. In a study on reaction time and sleep deprivation, the sleep-deprived groups' reaction times progressively worsened as their sleep debt increased (Belenky et al., 2002). After a recovery period where sleep patterns returned to normal, the slowed reactions times did not improve. A similar study on police recruits created a model to predict how lapses in reaction time are affected by sleep/wake cycles (Neylan et al., 2010). Their model predicts that the probability of a lapse occurring decreases $3.5 \%$ for every hour of sleep gained.

Partial sleep deprivation has been found to affect submaximal weight lifting more than maximal weight lifting (Reilly \& Edwards, 2007). Perceived effort as well as overall ability was affected after two successive nights of sleep restriction. An interesting finding in this study was that maximal effort was not affected by sleep deprivation. This finding is supported by a study on swimming performance that found no effect on back and grip strength or lung function after consecutive days of sleep restriction (Reilly \& Edwards, 2007). This finding is important, because participants in competitive collegiate sports do not usually operate at maximal exertion, with the exception of sprint-related sports such as track and swimming. Most sports rely on continued submaximal effort interspersed with brief periods of maximal effort. This combination of exertion levels could potentially mask the effects of sleep deprivation on overall performance if the body can respond appropriately when exerting maximal effort.

Sleep deprivation has also been associated with an increase in negative mood states, especially anger and depression (Reilly \& Edwards, 2007). The brain processes 
that regulate emotional states are highly sensitive to the quality and quantity of sleep (Wong, Lau, Wan, Cheung, Hui, \& Mok, 2013). One meta-analysis found that mood is affected at greater rates than cognitive or motor performance (Pilcher \& Huffcutt, 1996). These negative mood states are especially impactful on an individual's self-esteem, which can potentially impact mental health over a prolonged period of time (Wong et al., 2013). 


\section{Design}

Chapter 3: Methods

This was a cross-sectional descriptive study to examine sleep quality and quantity in collegiate-student-athletes attending Portland State University (PSU). This study attempted to ascertain whether student-athletes meet the recommended guidelines for sleep quality and quantity, and to examine the amount of time they spend on athletics and on academic activities.

\section{Participants}

The participants for this study were members of the various NCAA affiliated athletic teams at PSU. There were 229 student-athletes participating in athletics and enrolled in classes at PSU at the time of the study. The sports represented included women's basketball, women's golf, football, women's soccer, softball, men's and women's cross-country, men's and women's track and field, and women's volleyball. The age of the student athletes ranged from 18 to 23 years, and there were no gender or ethnic restrictions for participation. These student-athletes were selected because the principal investigator worked as an athletic trainer with the student-athletes at PSU.

\section{Procedures}

Data collection took place at PSU during the Spring Term of 2014. After receiving IRB approval, an e-mail was sent to the school-assigned e-mail addresses of the student-athletes, inviting them to participate in the study. The e-mail contained information about the survey, an informed consent form, and a link to the online survey, which was hosted on Surveymonkey. The athletes were selected from the current rosters on the official PSU athletics website. Athletes choosing to participate in the survey 
electronically signed the form and continued with the survey. Two weeks after the initial e-mail, another e-mail was sent to encourage those who had not yet participated to complete the survey. After data collection, the Pittsburgh Sleep Quality Index (PSQI) was scored, and data were coded and entered into a spreadsheet. Coding was used to conceal any information that could be used to identify participants, such as sport or major.

\section{Survey Instrument}

The first section of the survey collected demographic information, including gender, age, sport, current season status, year in school, cumulative GPA, major, and enrollment status. This section also contained questions about employment status, sleep disorders, concussions, and self-reported estimated time spent daily on athletic and academic activities. Self-reported time spent on athletics may include activities that are not included in the NCAA list of activities that count towards the 20-hour/week limit. This question was left intentionally broad to allow for a realistic picture of what the student-athletes are spending their time on, not just what counts towards the official time restraint.

The second section of the survey was the PSQI (Buysse et al., 1988). This instrument assesses sleep quality and can be used to categorize sleepers as "good" sleepers or "bad" sleepers. The PSQI examines sleep duration, sleep latency, sleep efficiency, sleep disturbances, daytime dysfunction, sleep quality, and the use of sleeping medications. This instrument has been validated for use in college-aged populations (Gerber et al., 2010; Lee \& Lin, 2010; Benham, 2010; Orzech, Salafsy, \& Hamilton, 
2011; Carney et al., 2006.). A score > 5 is considered to be a "bad" sleeper, while a score $\leq 5$ is considered a "good" sleeper. The survey instrument may be found in Appendix A.

\section{Data Analysis}

Before data analysis, all incomplete surveys were removed. Any responses that indicated a range of times were averaged for ease of analysis (e.g., 10-20 hours was recorded as 15 hours). For the cross-country and tennis teams, the two genders were combined due to a limited number of responses. The principal sleep-related dependent variables analyzed were self-reported amount of sleep (i.e., sleep duration; hours per night) and sleep quality (i.e., PSQI score). Data were also analyzed for self-reported amount of time spent per week on athletics and time spent per week on academics. These four dependent variables were examined by gender, class standing, sport, and season classification. Class standing was dichotomized into under classmen (freshmen and sophomores combined) and upper classmen (juniors and seniors combined). Season classification was self-reported based on the time the survey was completed (the first 3 weeks of May) as either in-season or out-of-season. Traditionally, in-season designates a team in its competition season, and out-of-season designates all other times. 
Chapter 4: Results

Forty-two student-athletes provided complete surveys and therefore comprised the sample for this study. Eleven of the 12 sports had at least one student-athlete respond to the survey, with men's basketball being the only sport not represented. There was at least one respondent at every class level. For the sake of analysis, the two respondents who classified themselves as a redshirt junior and a redshirt senior were classified as seniors. The age range was from 18-23 years and there were 29 female respondents and 13 male respondents. Eight respondents reported working during the school year, averaging 17.1 hours of work per week. Only one respondent reported a disorder that affects sleep habits (Attention Deficit Disorder). All of the respondents were enrolled full time, and the average GPA was 3.41 (4-point scale). The median bedtime of the group was 2330 and the median waking time was 0730. Raw data are provided in the supplemental file described in Appendix D.

\section{Sleep Duration}

The median sleep duration for the entire sample was 7 hours per night. The range of the responses was from 3-10 hours per night. Only one respondent self-reported averaging the recommended 10 hours of sleep per night, while 14 respondents were in the 8-9 hour per night range, which is recommended for the average college student. Figure 1 shows a comparison of sleep duration by gender, Figure 2 shows a comparison of sleep duration by class standing, and Figure 3 shows a comparison of sleep duration by season classification. Table 1 contains the median and ranges of sleep duration for each sport. 


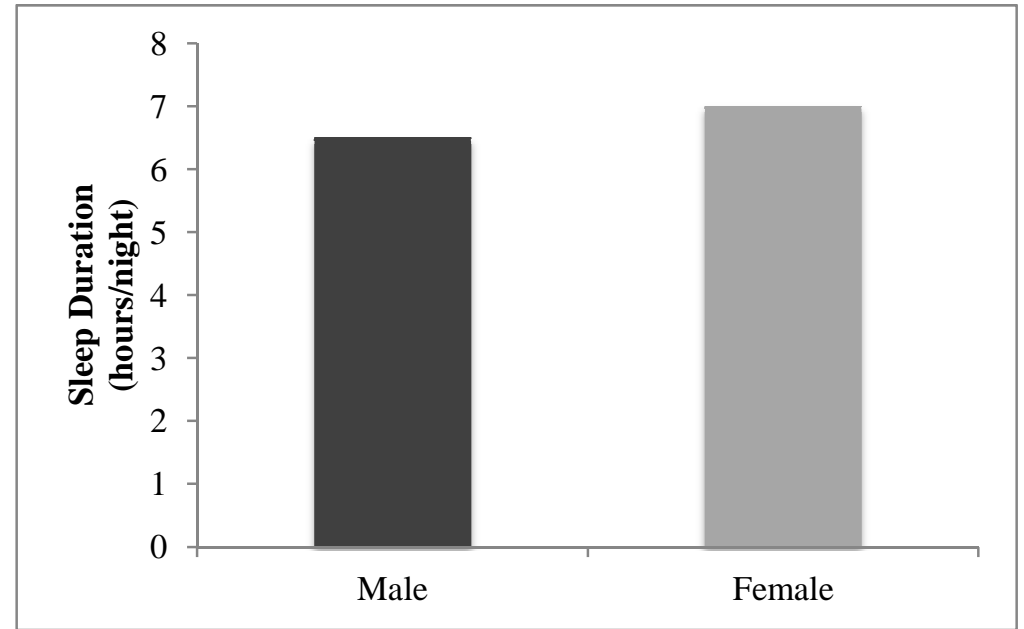

Figure 1. Sleep Duration by Gender (bars represent medians)

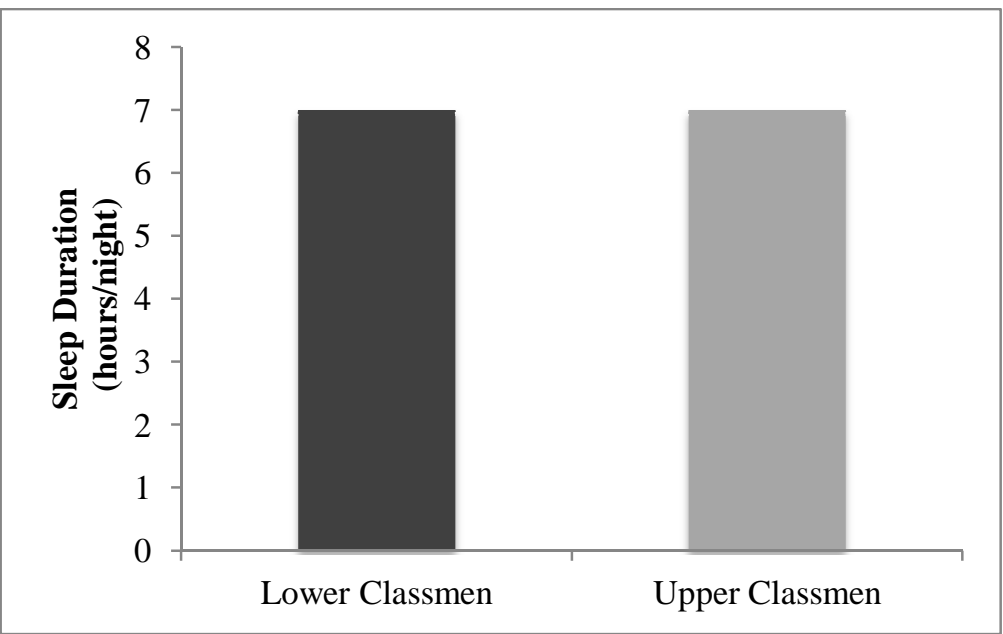

Figure 2. Sleep Duration by Class Standing (bars represent medians)

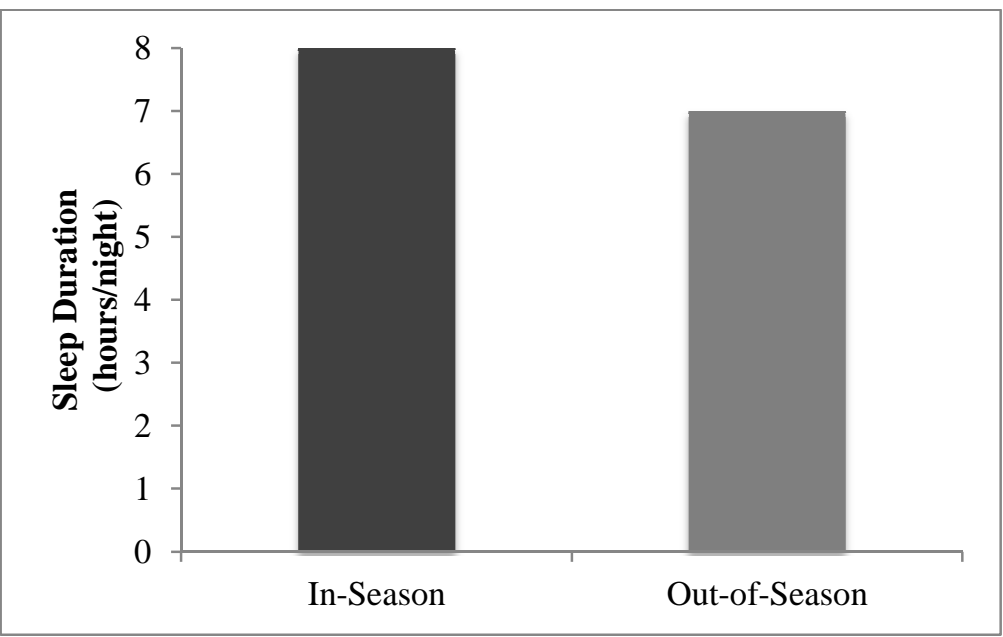

Figure 3. Sleep Duration by Season Classification (bars represent medians) 
Table 1. Sleep Duration and Sleep Quality by Sport (Data are reported as medians with ranges in parentheses.)

\begin{tabular}{|c|c|c|c|}
\hline Team & $\begin{array}{l}\text { Number of } \\
\text { Respondents }\end{array}$ & $\begin{array}{l}\text { Sleep Duration } \\
\text { (hours/night) }\end{array}$ & $\begin{array}{c}\text { Sleep Quality } \\
\text { Score }\end{array}$ \\
\hline Football & 5 & $\begin{array}{c}6 \\
(6-8)\end{array}$ & $\begin{array}{c}9 \\
(8-12)\end{array}$ \\
\hline Volleyball & 3 & $\begin{array}{c}7 \\
(7-8)\end{array}$ & $\begin{array}{c}9 \\
(8-10)\end{array}$ \\
\hline $\begin{array}{l}\text { Women's } \\
\text { Soccer }\end{array}$ & 5 & $\begin{array}{c}8 \\
(6.5-10)\end{array}$ & $\begin{array}{c}8 \\
(4-12)\end{array}$ \\
\hline Cross-Country & 2 & $\begin{array}{c}8.25 \\
(8-8.5)\end{array}$ & $\begin{array}{c}6 \\
(5-7)\end{array}$ \\
\hline $\begin{array}{l}\text { Women's } \\
\text { Basketball }\end{array}$ & 4 & $\begin{array}{c}6 \\
(6-7)\end{array}$ & $\begin{array}{c}9.5 \\
(7-14)\end{array}$ \\
\hline Softball & 7 & $\begin{array}{c}7 \\
(6-8)\end{array}$ & $\begin{array}{c}10 \\
(7-14)\end{array}$ \\
\hline Men's Track & 5 & $\begin{array}{c}6.5 \\
(6.5-9)\end{array}$ & $\begin{array}{c}9 \\
(6-13)\end{array}$ \\
\hline Women's Track & 6 & $\begin{array}{l}7.25 \\
(5-8)\end{array}$ & $\begin{array}{c}9 \\
(6-13)\end{array}$ \\
\hline Tennis & 2 & $\begin{array}{c}7 \\
(6-8) \\
\end{array}$ & $\begin{array}{c}11 \\
(10-12)\end{array}$ \\
\hline Women's Golf & 3 & $\begin{array}{c}8 \\
(3-9)\end{array}$ & $\begin{array}{c}7 \\
(7-11)\end{array}$ \\
\hline
\end{tabular}

\section{Sleep Quality}

The median sleep quality rating of the entire sample was 9 . The range of the sleep quality ratings was 4-14. Only three respondents had a rating that would classify their sleep quality as "good" (i.e., $\leq 5)$; two had sleep quality ratings of 4, and one had a sleep quality rating of 5. Forty respondents received a "bad" sleep rating (i.e., >5). Figure 4 shows a comparison of the median sleep quality rating by gender, Figure 5 shows a comparison of the median sleep quality rating by class ranking, and Figure 6 shows a comparison of the median sleep quality score by season classification. Table 1 contains the median and ranges of sleep quality ratings for each sport. 


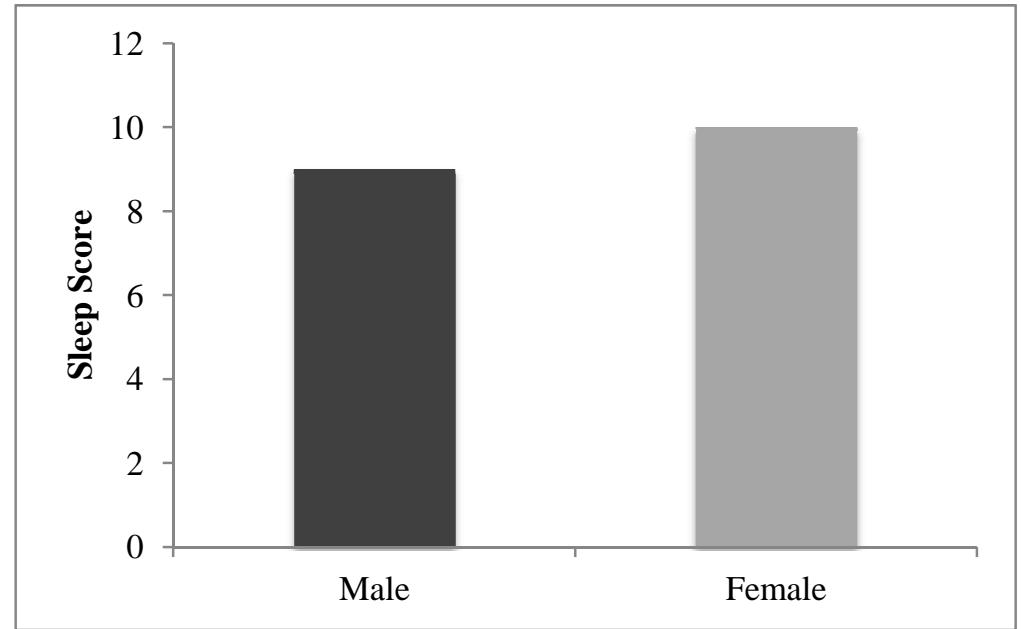

Figure 4. Sleep Score by Gender (bars represent medians)

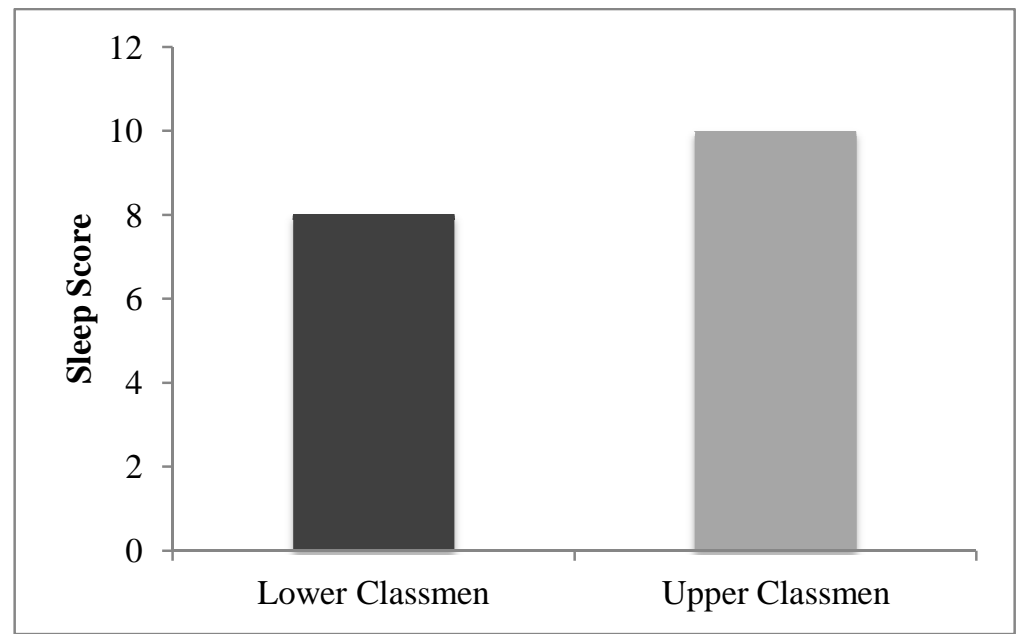

Figure 5. Sleep Score by Class Ranking (bars represent medians)

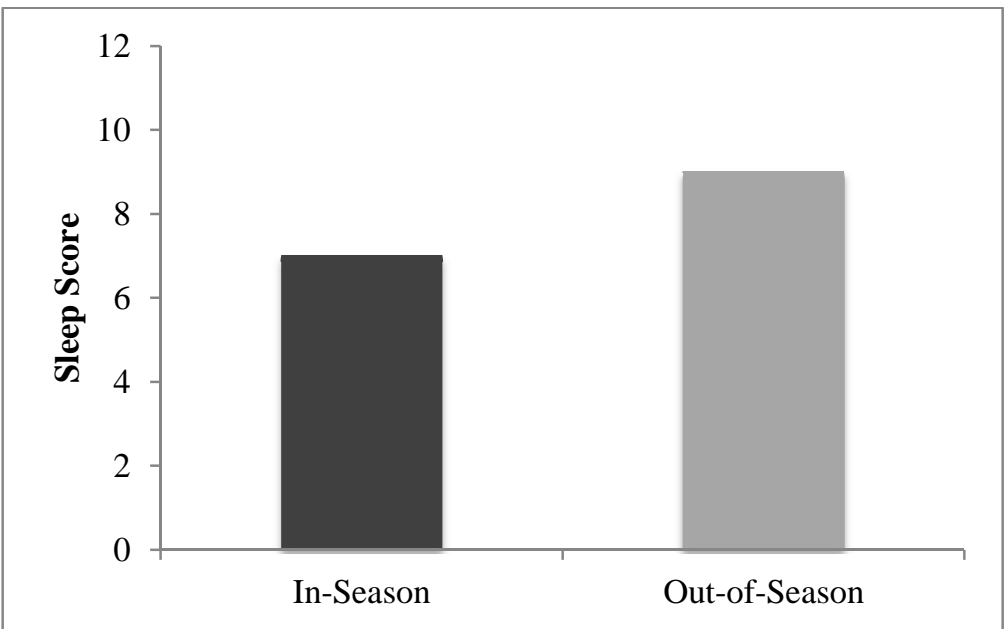

Figure 6. Sleep Score by Season Classification (bars represent medians) 
Time Spent on Athletics vs. Academics

For the entire sample, the median amount of time spent on athletics was 15.5 hours per week, with a range of 0-40 hours per week. Student-athletes participating in men's track $(n=5)$ reported the most time spent on athletics, with a median of 30 hours per week. Figure 7 shows a comparison of the weekly time spent on athletics and weekly time spent on academics by gender. Figure 8 shows a similar comparison by class ranking, and Figure 9 illustrates the comparison by season classification. Time spent on athletics and time spent on academics for each team can be seen in Table 2 .

Fourteen respondents reported spending more than 20 hours a week on their athletic activities (median 30 hours per week; range: 21-40 hours per week). The median sleep quality scores for this group was 7.5 and the median sleep duration was 8 hours per night. The median bedtime of this group was 2300 . The median amount of time spent on academics for this group was 12.5 hours per week, and their average GPA was 3.5.

For the entire sample, the median amount of time spent on academics was 15 hours per week, with a range of 0-45 hours per week. Student-athletes participating in men's track $(n=5)$ reported the most time spent on academics, with a median of 27.5 hours per week.

Thirteen respondents reported spending 20 hours or more per week on academics. The median sleep duration for this group was 7 hours per night and their median sleep quality score was 8 . The median bedtime for this group was 2300 . The median amount of time this group spent on athletics was 17 hours per week. Their average GPA was 3.5. 


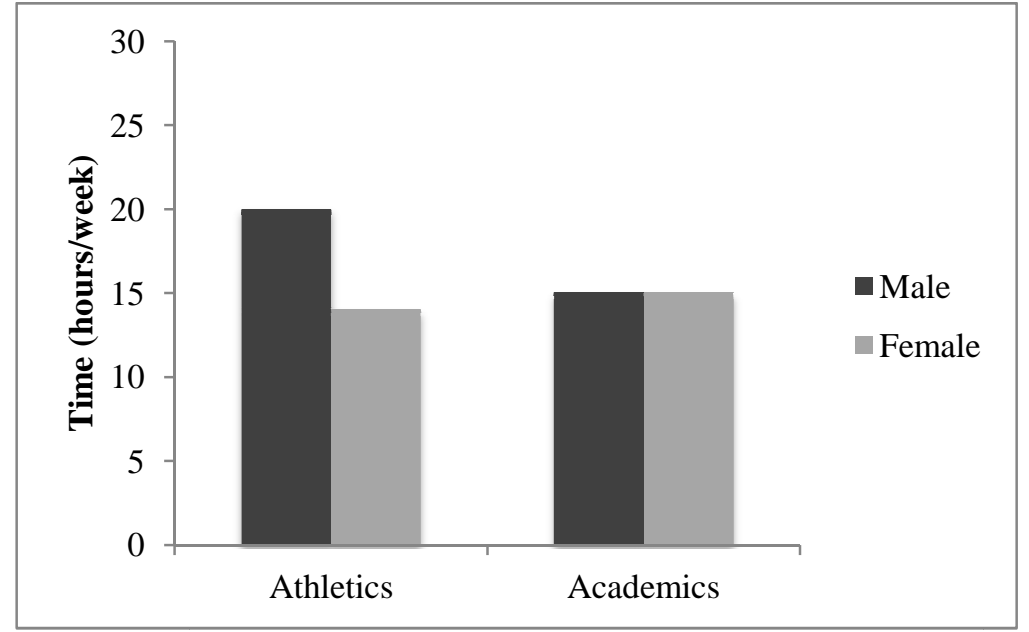

Figure 7. Time Spent on Athletics vs. Academics by Gender (bars represent medians)

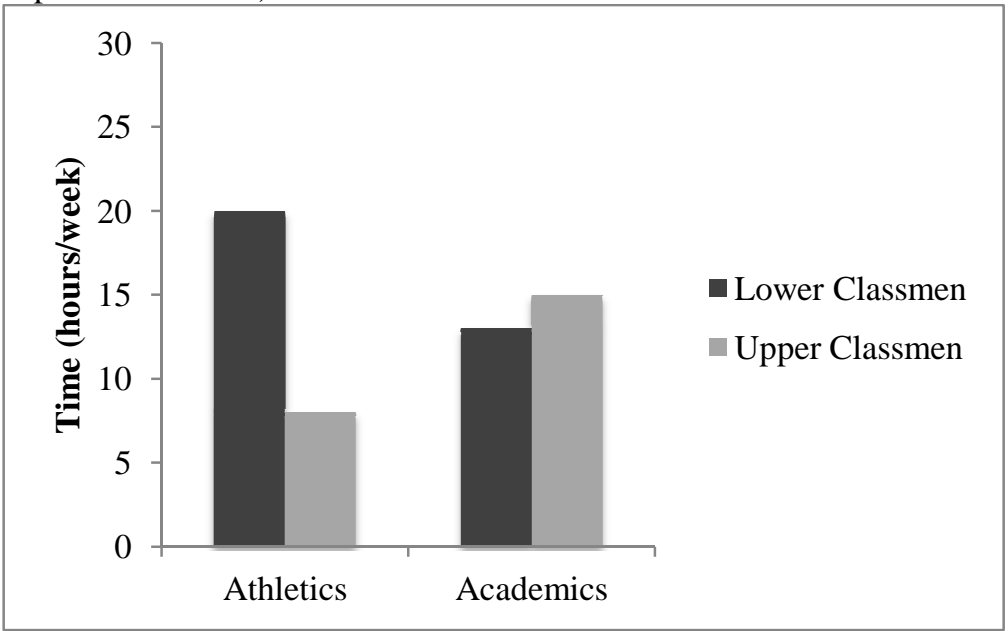

Figure 8. Time Spent on Athletics vs. Academics by Class Ranking (bars represent medians)

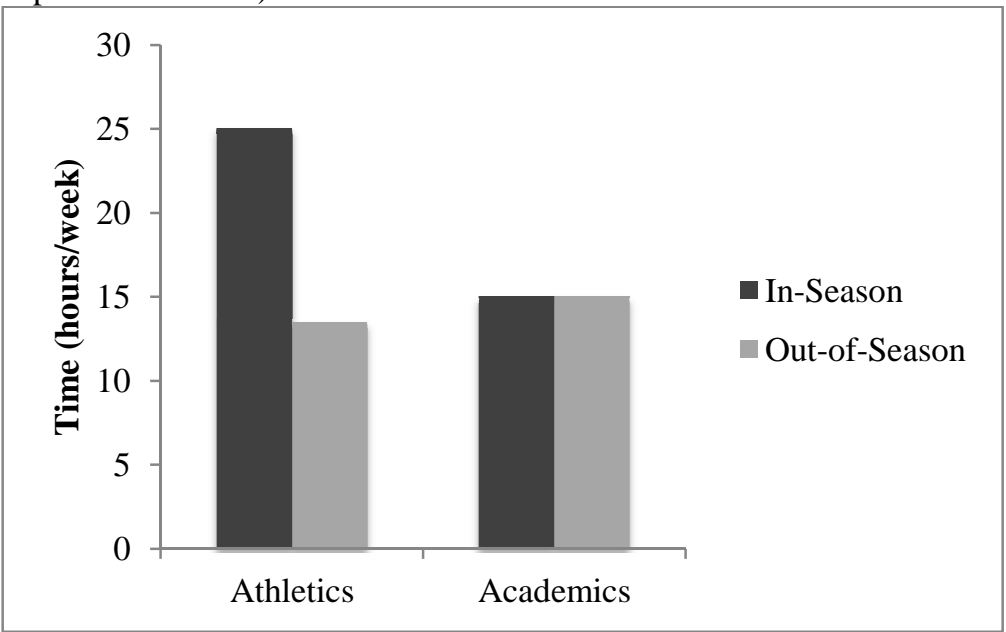

Figure 9. Time Spent on Athletics vs. Academics by Season Classification (bars represent medians) 
Table 2. Time Spent on Athletics and Academics by Team (Data are reported as medians with ranges in parentheses.)

\begin{tabular}{|c|c|c|c|}
\hline Team & $\begin{array}{l}\text { Number of } \\
\text { Respondents }\end{array}$ & $\begin{array}{c}\text { Time on } \\
\text { Athletics } \\
\text { (hours/week) }\end{array}$ & $\begin{array}{c}\text { Time on } \\
\text { Academics } \\
\text { (hours/week) }\end{array}$ \\
\hline Football & 5 & $\begin{array}{c}20 \\
(0-21)\end{array}$ & $\begin{array}{c}10 \\
(0-20)\end{array}$ \\
\hline Volleyball & 3 & $\begin{array}{c}10 \\
(7-15)\end{array}$ & $\begin{array}{c}10 \\
(0-35)\end{array}$ \\
\hline $\begin{array}{l}\text { Women's } \\
\text { Soccer }\end{array}$ & 5 & $\begin{array}{c}8 \\
(0-20)\end{array}$ & $\begin{array}{c}16 \\
(10-45)\end{array}$ \\
\hline Cross-Country & 2 & $\begin{array}{c}30 \\
(30-30)\end{array}$ & $\begin{array}{c}15 \\
(10-20)\end{array}$ \\
\hline $\begin{array}{l}\text { Women's } \\
\text { Basketball }\end{array}$ & 4 & $\begin{array}{c}14.75 \\
(4-40)\end{array}$ & $\begin{array}{c}12.5 \\
(6-30)\end{array}$ \\
\hline Softball & 7 & $\begin{array}{c}5 \\
(0-20)\end{array}$ & $\begin{array}{c}15 \\
(8-20)\end{array}$ \\
\hline Men's Track & 5 & $\begin{array}{c}30 \\
(8-30)\end{array}$ & $\begin{array}{c}27.5 \\
(4-40)\end{array}$ \\
\hline $\begin{array}{c}\text { Women's } \\
\text { Track }\end{array}$ & 6 & $\begin{array}{c}25 \\
(5-40)\end{array}$ & $\begin{array}{c}12 \\
(7-26)\end{array}$ \\
\hline Tennis & 2 & $\begin{array}{c}18.5 \\
(17-20)\end{array}$ & $\begin{array}{c}25 \\
(15-35)\end{array}$ \\
\hline Women's Golf & 3 & $\begin{array}{c}24 \\
(3-40)\end{array}$ & $\begin{array}{c}8 \\
(7-15)\end{array}$ \\
\hline
\end{tabular}

\section{In-Season vs. Out-of-Season}

The 13 self-identified in-season student-athletes reported spending 25 hours per week on athletic activities. In comparison, the 29 out-of-season student-athletes reported spending 13.5 hours per week on athletic activities. The in-season and out of season student-athletes had the same median amount of time spent on academic activities per week (15 hours). The in-season student-athletes also had a slightly higher GPA than the out-of-season student-athletes (average of 3.46 vs. 3.38, respectively). 
Although they reported having fewer time commitments related to athletics and academics, the out-of-season student-athletes had worse sleep habits than the in-season student-athletes. Both groups had similar median bedtimes (in-season: 2300; out-ofseason: 2330). Both groups also reported similar median sleep durations, with in-season student-athletes reporting 8 hours per night and out-of-season student-athletes reporting 7 hours per night. In-season student-athletes also scored better on their overall sleep quality rating than out-of-season student-athletes ( 8 vs. 9, respectively). Table 3 contains the median and ranges of sleep duration for in-season and out-of-season student athletes. Table 4 contains the median and ranges of time spent on athletics and time spent on academics for in-season and out-of-season student-athletes.

Table 3. Sleep Duration and Sleep Quality by Season Classification (Data are reported as medians with ranges in parentheses.)

\begin{tabular}{|c|c|c|c|}
\hline Variable & $\begin{array}{c}\text { Number of } \\
\text { Respondents }\end{array}$ & $\begin{array}{c}\text { Sleep } \\
\text { Duration } \\
\text { (hours/night) }\end{array}$ & $\begin{array}{c}\text { Sleep Quality } \\
\text { Score }\end{array}$ \\
\hline In-Season & 13 & $\begin{array}{c}8 \\
(3-9)\end{array}$ & $\begin{array}{c}7 \\
(5-13)\end{array}$ \\
\hline $\begin{array}{c}\text { Out-of- } \\
\text { Season }\end{array}$ & 29 & $\begin{array}{c}7 \\
(6-10)\end{array}$ & $(4-14)$ \\
\hline
\end{tabular}

Table 4. Time spent on athletics and academics by season classification (Data are reported as medians with ranges in parentheses.)

\begin{tabular}{|c|c|c|c|}
\hline Variable & $\begin{array}{c}\text { Number of } \\
\text { Respondents }\end{array}$ & $\begin{array}{c}\text { Time on } \\
\text { Athletics } \\
\text { (hours/week) }\end{array}$ & $\begin{array}{c}\text { Time on } \\
\text { Academics } \\
\text { (hours/week) }\end{array}$ \\
\hline In-Season & 13 & $\begin{array}{c}25 \\
(5-40)\end{array}$ & $\begin{array}{c}15 \\
(7-40)\end{array}$ \\
\hline $\begin{array}{c}\text { Out-of- } \\
\text { Season }\end{array}$ & 29 & $\begin{array}{c}13.5 \\
(0-40)\end{array}$ & $\begin{array}{c}15 \\
(0-45)\end{array}$ \\
\hline
\end{tabular}


Chapter 5: Discussion

As expected, the data show that PSU student-athletes' sleep quality is not rated as "good". Only three student-athletes had sleep quality rated as "good", leaving the overwhelming majority (93\%) classified as having their sleep quality rated as "bad". In addition, it was shown that in-season student-athletes spend more than 20 hours a week in athletics-related activities, with a median of 25 hours per week.

Although the sample size was small, the data suggest that introducing a sleep education program should be considered. Sleep hygiene is an important component of health that is often ignored by sports medicine professionals, and with such a large majority of student-athletes having very low sleep quality scores, this study clearly provides evidence that this health need is not being addressed. With subjective problems, such as sleep deprivation, among student-athletes, if coaches and medical personnel don't hear any complaints from athletes then they may be unaware that there might be a problem. Sleep plays an important role in allowing the body to heal from injury (Davenne, 2009), and inadequate sleep can have negative effects on performance. Failure to address the deficits in this area of health may not only compromise the health of student-athletes, but also result in suboptimal performance.

While further study is needed to determine causality between increased athleticsrelated time demands and a lack of sleep, there are modifications that can be made to improve the policies that are already in place. Even something as simple as expanding the list of activities included in the NCAA 20-hour cap could potentially have a beneficial effect on student-athlete sleep quality/quantity. Since travel can independently have an 
impact on sleep quality/quantity, it may be beneficial to require that coaches limit athletic activity after long travel weekends, where student-athletes spend a significant about of time away from their classrooms and familiar sleep environments.

As the national discussion on student-athlete welfare continues to develop, it is important to focus on all aspects of the student-athlete's life that are affected by participation in athletics. If participation in intercollegiate athletics is shown to negatively impact student-athlete health, then steps should be taken to educate student-athletes and improve policies so that an atmosphere can be created to promote healthy sleep habits.

\section{Limitations}

The most significant limitation of this study was the small sample size. The survey response rate was only $18.7 \%$, which limited the extent to which the data could be analyzed. Contacting student-athletes through e-mail is difficult because there is no way to know if they actually received-or read—the e-mail. This study was also limited by the time of year that it was conducted. Most of the sports had already finished their season, thereby limiting the number of student-athletes that were in-season; it also reduced the number of potential respondents since seniors who were no longer participating in their sport were not eligible. There was also a limitation due to the reliance on self-reported data. There is no way of knowing if students exaggerated the amount of time they spent on their athletics or on their academics, and there is also no way of knowing if they were truthful about their sleep habits. There is also no way of knowing what activities the respondents were including in their assessment of time spent on athletics. 


\section{Recommendations for Further Research}

Although there was such a small response rate, the data provide interesting information. Specifically, this study showed overwhelmingly, that PSU student-athletes' sleep quality was inadequate, and comparable results could be anticipated in similar populations. It would also be beneficial to administer the surveys during an athlete's inseason competition, and then compare the scores to their out-of-season data. This might provide some insight into whether or not there is any difference within individuals with regard to sleep health in-season versus out-of-season, which is presumably less timeconsuming. It would also be beneficial to compare results across the NCAA division classifications. Division 3 athletes do not receive scholarships for their athletic performance, which means that there is a greater emphasis placed on academics, and there should be fewer time demands related to athletics.

\section{Conclusions}

Overall, the data suggest that the sleep health of the student-athletes at Portland State University is not as good as it should be. Almost all of the student-athletes received a "bad" sleep quality rating, and the average of hours of sleep per night was also not at recommended levels. These data suggest that there is a need for further education of student-athletes so that they understand the importance of sleep and the impact it can have on athletic and academic performance. Not only are they hampering their ability to perform, but they are also missing out on potential performance benefits of obtaining additional sleep (Mah, Mah, Kezirian, \& Dement, 2011). It is recommended that policy changes be considered, such as a more comprehensive definition of "athletic activities", 
and a closer monitoring of the time commitment of student-athletes. Such policy changes could increase the amount of time available away from athletics for student-athletes to get enough sleep, and could lower the stress levels associated with not having enough time in the day to complete all necessary activities. If policy changes are implemented, improvements in athletic and academic performance may occur, and overall studentathlete health might improve. If steps are not taken to correct deficits in student-athlete sleep health, sports medicine professionals do a disservice to student-athletes; this may have a significant impact over the course of their athletic careers. 


\section{References}

Ahrberg, K., Dresler, M., Niedermaier, S., Steiger, A, \& Genzel, L. (2012). The interaction between sleep quality and academic performance. Journal of Psychiatric Research, 46(12), 1618-22. doi:10.1016/j.jpsychires.2012.09.008.

Belenky, G., Wesensten, N. J., Thorne, D. R., Thomas, M. L., Sing, H. C., Redmond, D. P., Russo, M. B., \& Balkin, T. J. (2003). Patterns of performance degradation and restoration during sleep restriction and subsequent recovery: A sleep dose-response study. Journal of Sleep Research, 12(1), 1-12. Retrieved from http://www.ncbi.nlm.nih.gov/pubmed/12603781.

Benham, G. (2010). Sleep: An important factor in stress-health models. Stress Health, 26, 204-214.

Bird, S. P., Laboratories, S. S., Wales, N. S., \& Wildcats, P. (2013). Athletic performance $\square$ : A brief review and recommendations. Strength and Conditioning Journal, 35(5), 43-47.

Brooks, G. A., Fahey, T. P., \& Baldwin, K. M. (2005). Exercise physiology: Human bioenergetics and its applications ( $4^{\text {th }}$ edition). New York, NY: McGraw Hill.

Buysse, D. J., Reynolds, C. F., Monk, T. H., Berman, S. R., \& Kupfer, D. J. (1988). The Pittsburgh Sleep Quality Index: A new instrument for psychiatric practice and research. Psychiatry Research, 28, 193-213.

Carney, C. E., Edinger, J. D., Meyer, B., Lindman, L., \& Istre, T. (2006). Daily activities and sleep quality in college students. Chronobiology International, 23(3), 623-37. doi:10.1080/07420520600650695.

Davenne, D. (2009). Sleep of athletes: Problems and possible solutions. Biological Rhythm Research, 40(1), 45-52.

Dettl, M. G. (2013). Do college athletes differ from college nonathletes in their sleep quality? (unpublished thesis). Ohio University, Athens. Retrieved January 26, 2014 from https://etd.ohiolink.edu/ap:10:0::NO:10:P10_ACCESSION_NUM:ohiou136637754 $\underline{6}$.

Dewald-Kaufmann, J. F., Orrt, F. J., Bogels, S. M., \& Meijer, A. M. (2013). Why sleep matters: Differences in daytime functioning between adolescents with low and high chronic sleep reduction and short and long sleep durations. Journal of Cognitive and Behavioral Psychotherapies, 13(1), 171-182. 
Durmer, J. S., \& Dinges, D. F. (2009). Neurocognitive consequences of sleep deprivation. Seminars in Neurology, 29(4), 320-39. doi:10.1055/s-0029-1237117.

Gaultney, J. F. (2011). The prevalence of sleep disorders in college students: Impact on academic performance. Journal of American College Health, 59(2), 91-7. doi:10.1080/07448481.2010.483708.

Gerber M., Brand, S., Holsboer-Trachsler, E., \& Pühse, U. (2010). Fitness and exercise as correlated of sleep complaints: Is it all in our minds? Medicine and Science in Sports and Exercise, 42(5), 893-901.

Gillen-O’Neel, C., Huynh, V. W., \& Fuligni, A. J. (2013). To study or to sleep? The academic costs of extra studying at the expense of sleep. Child Development, 84(1), 133-42. doi:10.1111/j.1467-8624.2012.01834.x.

Gillis, A. M. (1996). Why sleep? Bioscience, 46(6), 391-395.

Guezennec, C. Y., Sabatin, P., Legrand, H., Bigard, A. X. (1994). Physical performance and metabolic changes induced by combined prolonged exercise and different energy intake in humans. European Journal of Applied Physiology, 68, 525-530.

Hayes, L. D., Bickerstaff, G. F., \& Baker, J. S. (2010). Interactions of cortisol, testosterone, and resistance training: Influence of circadian rhythms. Chronobiology International, 27(4), 675-705.

Hobson, J. A. (1995) Sleep. New York, NY: Scientific American Library.

Hoddes, E., Zarcone, V., Smythe, H., Phillips, K., \& Dement, W. C. (1973). Quantification of sleepiness: A new approach. Psychophysiology, 10, 431-438.

Horne, J. A, \& Pettitt, A N. (1984). Sleep deprivation and the physiological response to exercise under steady-state conditions in untrained subjects. Sleep, 7(2), 168-79. Retrieved from http://www.ncbi.nlm.nih.gov/pubmed/6740061.

Lee, A. J. Y., \& Lin, W. H. (2010). Association between sleep quality and physical fitness in female young adults. Journal of Sports Medicine and Physical Fitness, 47, 462-467.

Lo, J. C., Groeger, J. A, Santhi, N., Arbon, E. L., Lazar, A. S., Hasan, S., Shantz, M. V., Archer, S. N., \& Dijk, D. J. (2012). Effects of partial and acute total sleep deprivation on performance across cognitive domains, individuals and circadian phase. PloS one, 7(9), e45987. doi:10.1371/journal.pone.0045987. 
Mah, C. D., Mah, K. E., Kezirian, E. J., \& Dement, W. C. (2011). The effects of sleep extension on the athletic performance of collegiate basketball players. Sleep, 34(7), 943-950.

NCAA (2013). NCAA division I manual. Retrieved October 15 from http://www.ncaapublications.com/productdownloads/D114.pdf.

Neylan, T. C., Metzler, T. J., Henn-Haase, C., Blank, Y., Tarasovsky, G., McCaslin, S. E., Lenoci, M., \& Marmar, C. R. (2010). Prior night sleep duration is associated with psychomotor vigilance in a healthy sample of police academy recruits. Chronobiology International, 27(7), 1493-508. doi:10.3109/07420528.2010.504992.

Öhström, E., \& Skånberg, A. (2004). Sleep disturbances from road traffic and ventilation noise: Laboratory and field experiments. Journal of Sound and Vibration, 271(1-2), 279-296.

Orzech, K. M., Salafsky, D. B., \& Hamilton, L. A. (2011). The state of sleep among college students at a large public university. Journal of American College Health, 59(7), 612-9. doi:10.1080/07448481.2010.520051.

Pilcher, J. J., \& Huffcutt, A. I. (1996). Effects of sleep deprivation on performance: A meta-analysis. Sleep, 19(4), 318-26. Retrieved from http://www.ncbi.nlm.nih.gov/pubmed/8776790.

Reilly, T., \& Edwards, B. (2007). Altered sleep-wake cycles and physical performance in athletes. Physiology \& Behavior, 90(2-3), 274-84.

doi:10.1016/j.physbeh.2006.09.017.

Scott, J. P. R., McNaughton, L. R., \& Polman, R. C. J. (2006). Effects of sleep deprivation and exercise on cognitive, motor performance and mood. Physiology \& Behavior, 87(2), 396-408. doi:10.1016/j.physbeh.2005.11.009.

Van Dongen, H. P. A, Maislin, G., Mullington, J. M., \& Dinges, D. F. (2003). The cumulative cost of additional wakefulness: Dose-response effects on neurobehavioral functions and sleep physiology from chronic sleep restriction and total sleep deprivation. Sleep, 26(2), 117-26. Retrieved from http://www.ncbi.nlm.nih.gov/pubmed/12683469.

Venter, R. E. (2012). Role of sleep in performance and recovery of athletes: A review article. South African Journal for Research in Sport, Physical Education, and Recreation, 34(1), 167-184. 
Walker, M. P., \& Stickgold, R. (2005). It's practice, with sleep, that makes perfect: Implications of sleep-dependent learning and plasticity for skill performance. Clinics in Sports Medicine, 24(2), 310-317.

Williamson, A. M., \& Feyer, A. M. (2000). Moderate sleep deprivation produces impairments in cognitive and motor performance equivalent to legally prescribed levels of alcohol intoxication. Occupational and Environmental Medicine, 57(10), 649-55. Retrieved from http://www.pubmedcentral.nih.gov/articlerender.fcgi?artid=1739867\&tool=pmcentr ez\&rendertype $=$ abstract

Wong, M. L., Lau, E. Y. Y., Wan, J. H. Y., Cheung, S. F., Hui, C. H., \& Mok, D. S. Y. (2013). The interplay between sleep and mood in predicting academic functioning, physical health and psychological health: A longitudinal study. Journal of Psychosomatic Research, 74(4), 271-7. doi:10.1016/j.jpsychores.2012.08.014. 


\section{Appendices}

Appendix A: Survey Instrument

1. Gender

_Male __ Female

2. Age:

3. NCAA Classification

Division 1 Division 2 _ Division 3 _ Other

4. $\operatorname{Sport}(\mathrm{s})$ :

5. Current Season Classification

In Season ___ Out-of-Season

6. Year in School

7. Major:

8. Enrollment Status

__ Full Time __ Part Time

9. Cumulative GPA:

10. Do you work during the school year?

_ Yes _ N No

b. If yes, how many hours per week?

11. Have you ever been diagnosed with a medical disorder that affects your sleep? Yes ___ No 
b. If yes, what disorder?

12. Are you currently suffering from a diagnosed concussion?

Yes No

b. If yes, when did you receive the concussion?

13. During the last week, how much time, on average, have you spent on athletics related activities?

14. During the last week, how much time, on average, have you spent on school related activities?

Pittsburgh Sleep Quality Index (PSQI)

1. During the past month, what time have you usually gone to bed at night? BED TIME

2. During the past month, how long (in minutes) has it usually taken you to fall asleep each night?

Number OF MINUTES

3. During the past month, what time have you usually gotten up in the morning? GETTING UP TIME

4. During the past month, how many hours of actual sleep did you get at night? (This may be different than the number of hours you spent in bed.)

HOURS OF SLEEP PER NIGHT 
For each of the remaining questions, check the one best response. Please answer all questions.

5. During the past month, how often have you had trouble sleeping because you...

Not during the Less than once Once or twice a Three or past month a week week more

times a

week
a. Cannot get
to sleep
within 30
minutes
b. Wake up in the middle
of the night
c. Have to get up to use the bathroom

\section{d. Cannot \\ breathe \\ comfortably \\ e. Cough or snore loudly}
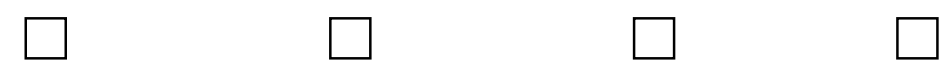

f. Feel too cold

g. Feel too

hot

h. Had bad dreams
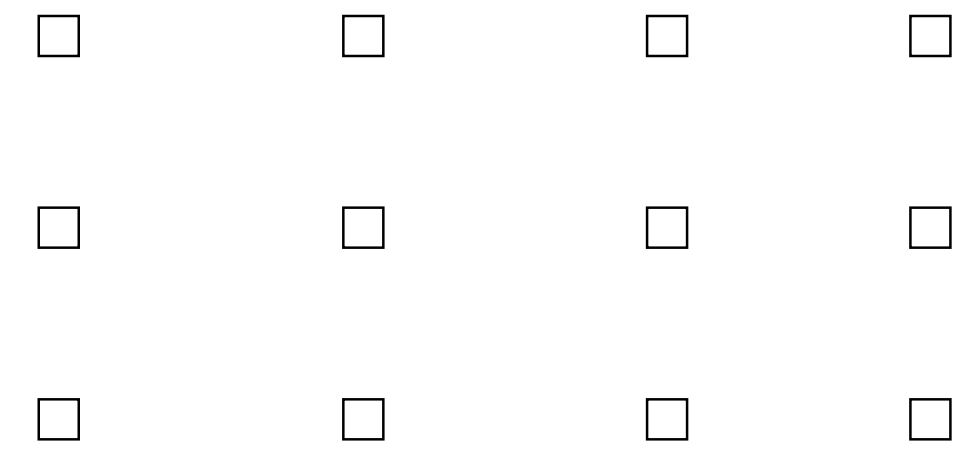

get


6. During the past month, how would you rate your sleep quality overall?

Very good Fairly good $\quad$ Fairly bad $\quad$ Very bad

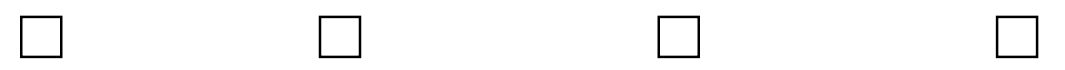

During the past month...

7. How often

Not during the Less than once Once or twice Three or more past month a week a week times a week

have you taken medicine to help you sleep (prescribed or "over the counter"?) 8. How often have you had trouble staying awake while driving, eating meals, or engaging in social activity?

9. During the past month, how much of a problem has it been for you to keep up enough enthusiasm to get things done?

$\begin{array}{cccc}\text { No problem at all } & \begin{array}{c}\text { Only a very slight } \\ \text { problem }\end{array} & \begin{array}{c}\text { Somewhat of a } \\ \text { problem }\end{array} & \begin{array}{c}\text { A very big } \\ \text { problem }\end{array} \\ \square & \square & \square & \square\end{array}$

10. Do you have a partner or roommate?

$\begin{array}{cccc}\begin{array}{c}\text { No bed partner or } \\ \text { roommate }\end{array} & \begin{array}{c}\text { Partner/roommate } \\ \text { in other room }\end{array} & \begin{array}{c}\text { Partner in same } \\ \text { room, but not same } \\ \text { bed }\end{array} & \begin{array}{c}\text { Partner in same } \\ \text { bed }\end{array}\end{array}$


If you do not have a roommate or bed partner, skip the following questions. If you have a roommate or bed partner, as him/her how often in the past month you have had...

a. Loud

Not during the Less than once Once or twice past month a week a week

Three or more times a week snoring<smiles>C1CCCC1</smiles>
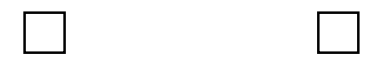

b. Long pauses between breaths while asleep

c. Legs twitching or jerking while you sleep

d. Episodes of disorientation or confusion during sleep e. Other (list below)
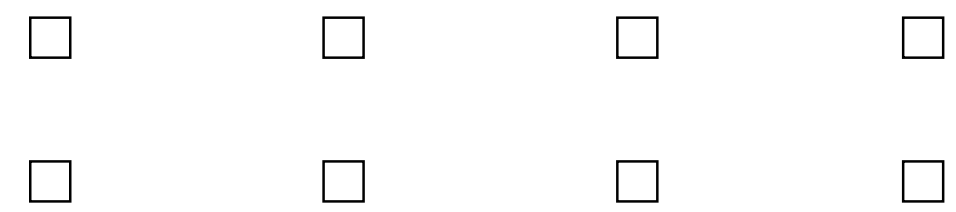
. 


\title{
Appendix B: Permission to Use Pittsburgh Sleep Quality Index
}

\author{
Buysse, Daniel to: Work \\ $2 / 10 / 14,1: 40 \mathrm{PM}$ \\ from: buyssedj@upmc.edu \\ RE: Request for permission to use PSQI \\ $\star ゅ ๖ カ x \mid 7$
}

Dear Mara,

You have my permission to use the PSQI for your research study. You can find the instrument, scoring instructions, the original article, links to available translations, and other useful information at www.sleep.pitt.edu under the Instruments tab. Please ensure that the PSQI is accurately reproduced in any on-line version (including copyright information). Please be sure to cite the 1989 paper in any publications that result.

Please note that Question 10 is not used in scoring the PSQI. This question is for informational purposes only, and may be omitted during data collection per requirements of the particular study.

This copyright in this form is owned by the University of Pittsburgh and may be reprinted without charge only for non-commercial research and educational purposes. You may not make changes or modifications of this form without prior written permission from the University of Pittsburgh. If you would like to use this instrument for commercial purposes or for commercially sponsored research, please contact the Office of Technology Management at the University of Pittsburgh at $\underline{412-648-2206}$ for licensing information.

Good luck with your research.

Sincerely,

Daniel J. Buysse, M.D.

Professor of Psychiatry and Clinical and Translational Science

University of Pittsburgh School of Medicine

E-1127 WPIC

3811 O'Hara St.

Pittsburgh, PA 15213

T: (412) 246-6413

F: (412) $246-5300$

buyssedj@upmc.edu

From: Work [mailto:mbirge@pdx.edu]

Sent: Monday, February 10, 2014 4:32 PM

To: Buysse, Daniel

Subject: Request for permission to use PSQI

Hello Dr. Buysse, my name is Mara Birge and I'm a graduate student at Portland State University in the health studies program. I am currently in the process of doing my thesis research on sleep quality of collegiate student athletes, and I was hoping to be able to use your PSQI scale for my research.

Thank you in advance,

Mara Birge, ATC

Graduate Assistant Athletic Trainer

Portland State University

P: $503-725-4073$

F: $503-725-5641$ 


\title{
Appendix C: Human Subjects Approval
}

\section{@ Portland $\underset{\text { UNIVERSITY }}{\text { State }}$}

\author{
Post Office Box $751 \quad 503-725-2227$ tel \\ Portland, Oregon 97207-0751 503-725-8170 fax \\ Human Subjects Research Review Committee \\ hsrrc@lists.pdx.edu
}

Date: April 30, 2014

To: Gary Brodowickz, Mara Birge

From: Karen Cellarius, HSRRC Chair

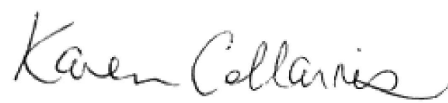

Re: HSRRC approval for your project titled, "Sleep Quality and Quantity of Collegiate Student Athletes” HSRRC Proposal \#

Approval-Expiration: April 30, 2014 - April 29, 2015

Review Type: Expedited, Category 7

In accordance with your request, the PSU Human Subjects Research Review Committee has reviewed your request for approval of the project referenced above for compliance with PSU and DHHS policies and regulations covering the protection of human subjects. The Committee is satisfied that your provisions for protecting the rights and welfare of all subjects participating in the research are adequate, and your project is approved. Please note the following requirements:

Approval: You are approved to conduct this research study only during the period of approval cited above; and the research must be conducted according to the plans and protocol submitted.

Consent: Signed consent is required from all participants in this study.

Changes to Protocol: Any changes in the proposed study, whether to procedures, survey instruments, consent forms or cover letters, must be outlined and submitted to the Committee immediately. The proposed changes cannot be implemented before they have been reviewed and approved by the Committee.

Continuing Review: This approval will expire on 4/29/2015. It is the investigator's responsibility to ensure that a Continuing Review Report on the status of the project is submitted to the HSRRC two months before the expiration date, and that approval of the study is kept current. The Continuing Review Report is available at www.rsp.pdx.edu/compliance_human.php and in the Office of Research and Strategic Partnerships (RSP).

Adverse Reactions and/or Unanticipated Problems: If any adverse reactions or unanticipated problems occur as a result of this study, you are required to notify the Committee immediately. If the issue is serious, approval may be withdrawn pending an investigation by the Committee.

Completion of Study: Please notify the Committee as soon as your research has been completed. Study records, including protocols and signed consent forms for each participant, must be kept by the investigator in a secure location for three years following completion of the study (or per any requirements specified by the project's funding agency).

If you have questions or concerns, please contact the Office of Research Integrity in the PSU RSP at hsrrc@ pdx.edu. 
Appendix D: Supplemental File: Raw Data

Name: Birge Raw Data

File Type: CSV

Size: $47 \mathrm{~KB}$

Required application software: Microsoft Excel or similar program 